\title{
ERRATUM
}

doi:10.1038/nature08492

\section{Dense packings of the Platonic and}

\section{Archimedean solids}

S. Torquato \& Y. Jiao

Nature 460, 876-879 (2009)

In Figure 1 of this letter, in the top row 'A1' was incorrectly listed as 'P6'. The correct figure is shown below.

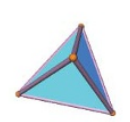

P1

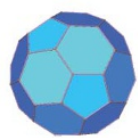

$\mathrm{A} 2$

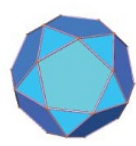

A8

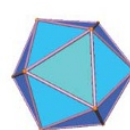

P2

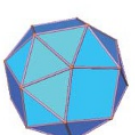

A3

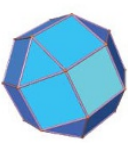

A9



P3

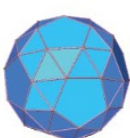

A4

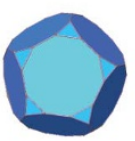

A10
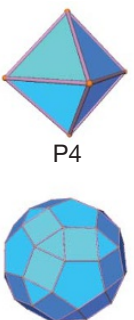

A5



A11
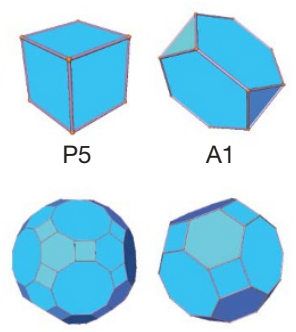

A6

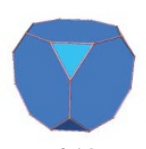

A12
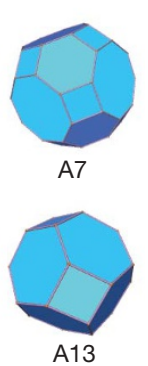